\begin{tabular}{c} 
Volume and Issues Obtainable at Center for Sustainability Research and Consultancy \\
Journal of Business and Social Review in Emerging Economies \\
ISSN: 2519-089X (E): 2519-0326 \\
Volume 3: Issue 2December 2017 \\
CSRᄃ \\
Journal homepage: $\underline{\text { www.publishing.globalcsrc.org/jbsee }}$ \\
\hline
\end{tabular}

\title{
Role of Transformational Leadership in Effective Strategic Implementation with the Moderating Effect of Organizational Culture \\ ${ }^{1}$ Onuma Suphattanakul \\ Lecturer, Department of Social Science and Apply Science, Faculty of Commerce and Management, Prince of Songkla University, Trang Campus, Thailand \\ onuma.su@psu.ac.th
}

\begin{tabular}{l}
\hline ARTICLEDETAILS \\
\hline History \\
Revised format: Nov 2017 \\
AvailableOnline: Dec 2017 \\
\\
\hline Keywords \\
Strategic Implementation, \\
Transformational Leadership, \\
Organizational Culture, \\
Municipality, \\
Thailand
\end{tabular}

JEL Classification:

D78, D79

\begin{abstract}
Purpose:This study evaluates the role of transformational leadership in effective strategic implementation. The purposes of this study are; first, to examine the degree of transformational leadership of administrative officials; second, to assess the degree of effective strategic implementation; third, to investigate the impact of transformational leadership on effective strategic implementation. Finally, this study examines the roles of organizational culture as a moderator of the association between transformational leadership and effective strategic implementation.

Methodology: This study uses the case study of municipalities in Trang Province in Thailand.This research employs quantitative methods. The questionnaires are collected from administrative officials of municipalities in Trang Province. Descriptive statistics are used to analyse the data. This study uses Pearson correlation analysis to achieve the associations between two variables. In addition, regression analysis is applied as a suitable statistical tool to test the hypotheses.

Implication:This study combined the framework of strategic management, leadership, and organizational culture for testing the conceptual model. The study is particularly useful for improving the roles of administrative officialsin order to achieve effective strategic in municipalities.
\end{abstract}

(C) 2017 The authors, under a Creative Commons AttributionNonCommercial 4.0

Corresponding author's email address: onuma.su@psu.ac.th

Recommended citation:Suphattanakul, O. (2017).The Role of Transformational Leadership in Effective Strategic Implementation with the Moderating Effect of Organizational Culture.Journal of Business and Social Review in Emerging Economies, 3(2),253-262.DOI:https://doi.org/10.26710/jbsee.v3i2.80

\section{Introduction}

Since the economic crisis in 1997, the Thai Royal government has determined to improve the public administration and increase performance in public sector. The Thai government has initiated strategies to reform government agencies comprising local government. Among many changes including internal and external factors, efforts to strengthen the government strategies have been placed as a main stage by the government. The Thai government has many attempts to create new strategies approved by the Office of the Public Sector Development Commission (OPDC) in order to increase public organizational performance. The strategies aim to improve service quality, competencies of servants, public participation, and governance in administration. They also influence public organizational performance and its sustainable development. Therefore, strategic public management becomes an important tool to give a strong impact on public sectors' success. Strategic management is generally originated in the business sector. It focuses on the relationship between the external and internal environment and mission, 
vision, and objective of the organization. In the recent years, strategic management has been transformed to the public sector. The strategic management in public sectors has been adopted as a response to public needs and requirements. It is considered in increasing public service delivery, efficiency and effectiveness, resources management, and governance.

Strategy implementation is the key process of strategic management to obtain the desired results after the strategy has formulated. Although strategy formulation is a difficult task and important for making strategy work, strategic implementation is even more difficult (Hrebiniak, 2006). It is the challenge and creative process of strategic management. In addition, it covers restructuring the organization, resources management, decision-making processes, and human resource management. This requires organization to create objectives, formulate strategy, motivate employee, and allocate resources to accomplish strategies. According toSteiner (2004), strategic implementation is a main step that includes compensation, evaluation, motivation, and controlling. It challenges to transfer plans to actions that actually lead to the effectiveness of organizational performance. Thus, this study seeks to evaluate effective strategic implementation as organizational performance.However, many organizations especially public organizations struggle to turn plans into actions that will enable the strategies to be successful (Dewar et al., 2011). Due to various factors effecting strategic implementation such as organizational structure, leadership, motivation, organizational culture, successful strategy formulation does not all guarantee successful strategy implementation (Barnat, 2014). Jooste \&Fourie (2009) noted that the high failure rate of strategic implementation efforts is well documented, and many barriers to effective strategic implementation exist. Excellently formulated strategies will fail if they are not properly implemented. Noble (1999) noted that the failure of the best formulated strategies may come from unsuccessful implementation. In, addition, many strategy studies claim that most of strategy implementation efforts fail (Ashkenas\& Francis, 2000; Beer \&Nohria, 2000; Jonk\&Ungerath, 2006; Raps, 2004; Atkinson, 2006). However, many studies indicate that strategic implementation have received less attention from both academics and practitioners compared to strategic formulation )Chaimankong\&Prasertsakul, 2012(. Thus, it is essential to indicate that effective strategy implementation is based on organizational dimension as transformational leadership.

Strategic leadership is perceived as an important component of effective strategic management. Bryson (1989) noted that strategic leadership creates organization's change and conducts the direction, encouragement and motivate behavior of workers. Leadership capacity makes directions for the organization, allocates resources, and creates activities tosupport those directions. Public sector leaders focus their organizations on strategic directions and strategic changes. They also encourage employees by giving power and authority to make decisions. Gracia-Morales et.al (2012) defined transformational leadership as leadership style that focuses on increasing interests of the organization's members and supports them to reach their goals. Thamrin (2012) found that transformational leadership has a positive influence on employees' performance. It is mentioned that this style of leadership can bring significant changes to employees' work. According to Bass (1999); Bass \&Avolio (2000), transformational leadership intended to the organization's goals and employees' internalization and encourage to increase organizational performance and their benefits.Herold, Fedor, Caldwell, \&Lui (2008) concluded that transformational leadership approaches have been successful in promoting change. Thus, transformational leadership is required to complete effectively strategic implementation.

In addition, this study addresses organizational culture as one of core competencies of an organization. It is defined as values and beliefs that relate to an organization's behavior and norm. In order to increase effective strategic implementation, it must relate to the organizational culture. The previous studies found that organizational culture seemed to have some substantial influence on organization's strategy (Mantere, 2000; Van Der Maas, 2008; Van Buul, 2010). Therefore, organizational culture is required as a combining and encouraging factor considered in the implementation process. It is essential to measure organizational culture that will help organization achieves strategic implementation. However, only a few studied implicitly the effect of culture on strategic implementation (Mantere, 2000; Van Der Maas, 2008). It is 
important to assess the underlying assumptions related to organizational culture and effective strategic implementation. Thus, this study emphasizes on the moderating effect of organizational culture on the relationship between transformational leadership and effective strategic implementation.

Among the levels of government, local government, particularly municipality is considered as organization that implements strategies. Many external factors influence strategic implementation in local government in the Thailand. In addition, the reforms of local administration by central government by encouraging various tools which focus on performance measurement. Local authorities need to develop the capacity of implementation systems and processes in order to achieve the organizational goals. However, the failure of strategy implementation efforts in Thai local governments is well accepted, and many barriers to effective strategic implementation still exist (Nagai et al., 2008). In addition, Mektrairatet al. (2009) concluded that a lack of strategic leadership has been identified as one of the main barriers to effective strategic implementation in Thai local governments.

Thus, this study addresses the importance of municipalities to the clients. Municipality is a basic government organization which provides public services to citizens. It is also one of the means to achieve the ends of decentralization. It is important to focus on the role of municipalities' leadership and organizational culture that influence effective strategic implementation. Therefore, this study focuses on the role of transformational leadership in effective strategic implementation in municipalities in Trang Province, Thailand. In addition, this study tries to investigate organizational culture as a moderator variable that may effect on the relationship between transformational leadership in effective strategic implementation.

\section{Research Question}

This study links the issue of effective strategic implementation with the study of leadership style and organizational culture. Thus, this study seeks to ask the following research questions:

i. What is the perceived role of transformational leadership of administrative officials in municipalities in Trang Province?

ii. What is the degree of effective strategic implementation in municipalities in Trang Province?

iii. What is the role of transformational leadership in effective strategic implementation in municipalities in Trang Province?

iv. Howdoes organizational culture moderate the relationship between transformational leadership and effective strategic implementation in municipalities in Trang Province?

\section{Research Objectives}

This study tries to accomplish the following objectives.

i. To investigate the perceived role of transformational leadership of administrative officials in municipalities in Trang Province.

ii. To assess the degree of effective strategic implementation in municipalities in Trang Province.

iii. To examine the role of transformational leadership in effective strategic implementation in municipalities in Trang Province.

iv.To investigate how organizational culture moderates the association between transformational leadership and effective strategic implementation in municipalities in Trang Province.

\section{A Review of the Literature}

\subsection{Resource-based View}

Resource-based View (RBV) is based on the concept of organization's resources and the view of the organizational capabilities that provides the basis for its strategy. RBV argues against a theoretical framework that describes organizations that are successful in creating competitive advantage and sustainability (Eisenhardt\& Martin, 2000) .The resources of anorganization possesses include all assets as management skills, organizational processes, organizationalcapabilities to achieve organizational effectiveness.Zheng, Yang\& McLean (2010)concluded that many studies have been considered widely in 
the relationship between leadership, organizational culture, and strategy with organizational effectiveness.

\subsection{Concept of Effective Strategic Implementation}

Strategy implementation is an involving circle between strategic formulation and control. Strategy implementation has become the most significant management challenge. However, Rajasekar (2014) founded thatstrategy implementation is more problematic than strategy formulation. In order to achieve strategy implementation, it involves many keys as leadership abilities, resources management, accuracy planning, and the confidence in strategy.According to Mushtaq (2008), suitable leadership is required to reach the organizations goals and also effective strategy implementation.Barnat (2014) concluded that implementing strategy depends on change management which improves organizational performance. The motivating manager became a key determinant to make changes for strategic implementation. The study concluded that motivational leadership, organizational performance, and changing plan to action affect strategic implementation.

\subsection{Concept of Transformational Leadership}

To successfully implement an organization's strategy, it must focus on the leaders who create, monitor, encourage and reward. Thus, the leadership is required to effect effective strategic implementation. Sullivan \& Decker (2012) noted that transformational leadership focuses on organizational change through a commitment to the organization's vision. The findings of the study show the impact of transformational leadership on organizational performance positively.Transformational leadership has an effect to organization's benefits by creating strategic organizational change (Waldman, Javidan, \&Varella, 2004).Thobani (2011) found that the roles of middle manager assist the effective strategic implementation. Omondi (2013) mentioned that three organizational factors affecting effective strategy implementation consist of policy regulations, management competencies and the resource allocations to define successful strategy implementation. Cavazotte, Moreno \& Bernardo (2013) examined the influences between transformational leadership and subordinate formal and contextual performance. They found that higher task performance is created by transformational leadership.Gang, In-Sue On, Courtright, \& Colbert (2011) found that transformational leadership was positively associated to individual performance, team performance, and also organization performance.

\subsection{Concept of Organizational Culture}

Dodeket al. (2010) noted that organizational culture is to an organization what personality is to the individual. Ahmadi, Salamzadeh, Daraei, \& Akbari (2012) studied the relationship between organizational culture and strategic implementation. Results clear up that the role of culture has an influence on strategic implementation. In addition, Fey \& Denison (2003) found that organizational culture has a positive association with effectiveness and performance. Robbins \&Sanghi, (2007) concluded that there is a relationship between cultural traits and organizational effectiveness. In addition, Alvesson (1989) defined that the acceptance of organizational culture is an important tool for accomplishing performance. Thus, organizational culture is measured as a key driver in strategy implementation process (Schein, 2009).

\section{The Conceptual Framework}

This study investigates the impact of transformational leadership and organizational culture on strategic implementation in municipalities in Trang Province, Southern Thailand. This study is based on the concepts of Strategic Management and Results Based Management to measure a successful strategic implementation as an organizational performance in public sector.Thus, the conceptual foundations of this study consist of three concepts as transformational leadership, organizational culture, and strategic implementation. In this study, transformational leadership is considered the major independent variable whereas the dependent variable is effectivestrategic implementation. In addition, a conceptual framework is constructed to include the moderating organizational culture factors that might have an effect on the relationship between transformational leadership and effective strategic implementation which is shownin figure 1 . 


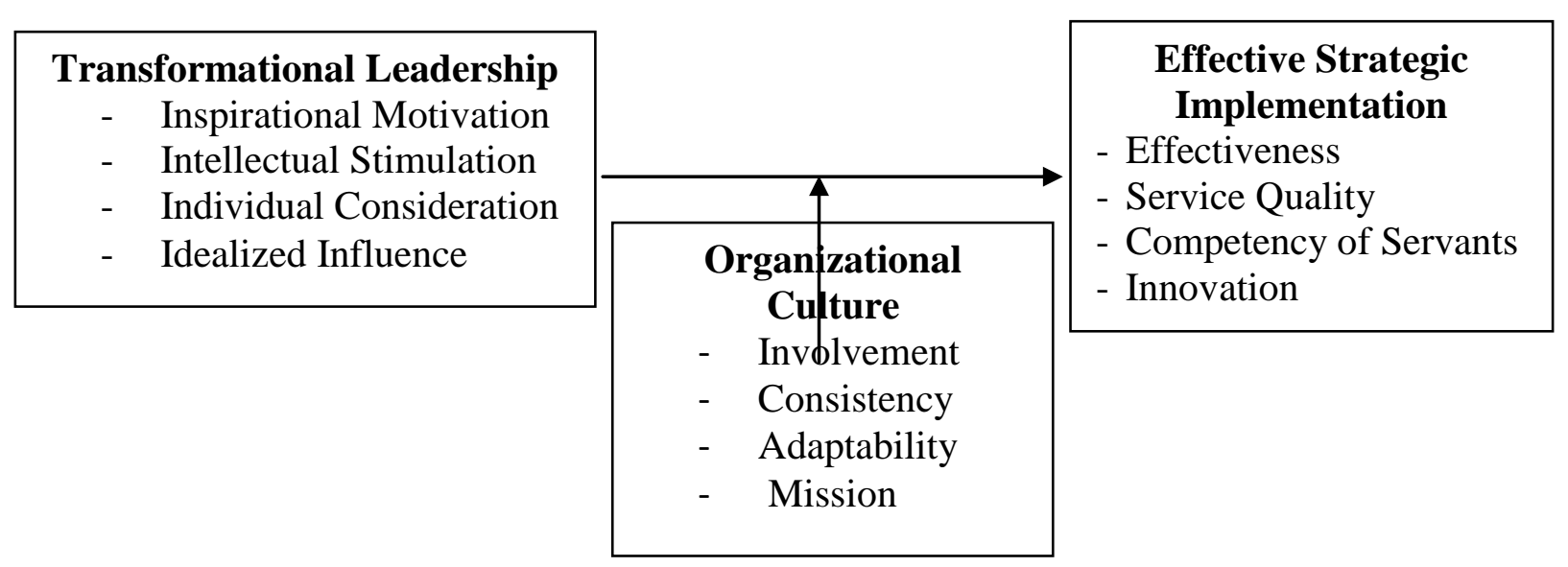

Figure 1 Conceptual Framework of the Study

\section{Hypothesis}

The role of transformational leadership has been extensively emphasized as the key factor of effective strategic implementation.Various studies assert association between leadership and strategic implementation (Nutt, 1986; Noble, 1999; Schaap, 2006; Cater \&Pucko, 2010). The hypothesis is followed.

H1: Transformational leadership has a positive impact on effective strategic implementation. Organizational culture influences results in the success or failure of strategic implementation. It makes complete sense that organizations would consider culture in strategic management. Many studies have also showed a significant influences between organizational culture and strategic implementation (Ahmadi, Salamzadeh, Daraei, \& Akbari, 2012; Lismen, Margaret \& Ed Snape, 2007; Schein, 2009). The hypothesis is followed.

H2: Organizational culture moderates the relationship between transformational leadership and effective strategic implementation.

\section{Contribution of the Study}

This research seeks to assess the extent of the degree of transformational leadership and effective strategic implementation in municipalities in Trang Province. In addition, this study examines the role of transformational leadership in effective strategic implementation with the moderating effect of organizational culture. The results are to:

i. Integrate the framework of strategic management, organizational culture, and leadership for testing the conceptual framework in municipalities in Trang Province.

ii. Provide a conceptual understanding of strategic management in public sector which leads to preferable replies by municipalities' officials in order to achieve strategic implementation.

iii. Advise the administrative officials to consider in their leadership and organizational culture in order to successfully strategy implement.

iv. Improvemunicipalities' capabilities in order to achieve the strategic accomplishment.

\section{Scope of the Study}

This study employs quantitative method. The target population of this study consists of administrative officials in municipalities in Trang Province, Thailand. The research starts from 2017 and completes within two years.

\section{Research Methodology}

\subsection{Research Design}

Descriptive research is designed to obtain data in order to define the relationship between variables. This 
research employs quantitative methods. The questionnaires are collected from administrative officials of municipalities in Trang Province. This study employs a deductive model to provide evidence for testing hypothesis.

\subsection{Population and Sample Sizes}

In this study, the target population is administrative officials who are working in three types of municipalities in Trang Province. The total population is around 410 administrative officials. According to the sampling table by Krejcie\& Morgan (1970), the total sample size is 201 respondents. The Proportional Stratified Random Sampling is used as a method of sampling which is shown in Table 1.

Table1 Number of Population and Sample Size
\begin{tabular}{|l|c|c|}
\hline Type of Municipality & Administrative Official & Sample \\
\hline Nakhon Municipality & 35 & 16 \\
Muang Municipality & 25 & 14 \\
Tambon Municipality & 350 & 171 \\
\hline Total & $\mathbf{4 1 0}$ & $\mathbf{2 0 1}$ \\
\hline
\end{tabular}

Source:Office of Local Administration of Thailand, 2017

\subsection{Measurement}

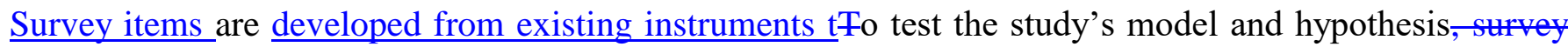
items were developed from existing instruments. Specifically, the components of three variables as strategic implementation, transformational leadership, and organizational culture will be assembled.

\subsubsection{Measuring Effective Strategic Implementation}

Balanced Scorecard created by Kaplan \& Norton (1992) has implemented to assess organizational performance. To measure performance in Thailand's public organizations, the Office of the Public Sector Development Commission of Thailand (OPDC) applied Balanced Scorecard which consists of four elements as effectiveness of strategic plan implementation, quality of service delivery, efficiency of public work, and organization development. This study adapts the measurements applied by OPDC (OPDC Handbook, 2009) to measure effective strategic implementation in public organization. The instrument consists of four perspectives as: 1) Effectiveness, 2) Service Quality, 3) Competency of Servants, and 4) Innovation.

\subsubsection{Measuring Transformational Leadership}

This study adapts the Survey of Transformational Leadership (STL) developed by Avolio, Bass, Walumbwa, \& Zhu (2004) to measure transformational leadership. The STL has been comprehensively used and is regarded a well-validated measure of transformational leadership (Awamleh\& Gardner, 1999). In addition, STL is comprehensive instruments and widely available to evaluate transformational leadership. The instrument consists of four dimensions as:1) Inspirational Motivation, 2) Intellectual Stimulation, 3) Individual Consideration, and 4) Idealized Influence.

\subsubsection{Measuring Organizational Culture}

Organizational culture is an important determinant of organizational success. This study adopts the Denison Organizational Culture Survey and Theory established by Fey \& Denison-(Fey \& Denison,(2003) to determine public sector organizational culture.The Denison model is a comprehensive organizational culture model. This instrument is used because of its theoretical foundation, and its use in past studies of both the public and private sectors. The instrument consists of four dimensions as: 1)involvement, 2) consistency, 3) adaptability, and 4)mission.

All perceptions of respondents are measured through a five-point Likert scale $(1=$ strongly disagree to $5=$ strongly agree).

\subsection{Data Collection Process}


The data collection process starts in 2017. Thirty questionnaires of the respondents are used in a pilot study to estimate the research instruments while questionnaires are distributed to the administrative officials in municipalities in Trang Province, Thailand.

\subsection{Validity and Reliability}

This study examined the content validity and construct validity. Content validity of the instrument was achieved by adopting the items that were used in the previous studies and gathering experts' opinions. According to Hair et al. (2006), seeking opinions from academics who are experts in their particular areas leads to proper assessment of the content validity. Thus, to obtain feedbacks on the instruments, the questionnaires were sent to the experts in the academic area of this study at Prince of Songkhla University, Thailand. Based on the comments, item corrections were carried out to rewrite and to ensure the wording and clarity of the items. Before deciding on the actual measurement to be used, a pilot study of a sample of 30 respondents was distributed to administrative officials. The reliability value for each measurement was computed for a pilot study. The reliability analysis was used on the variables to test the internal consistency of all instruments. The results are presented in Table 2.

According to Hair et al. (2006), Cronbach's alpha values less than 0.60 is identified to be poor, 0.60 to 0.70 is moderate, 0.70 to 0.80 is good, 0.80 to 0.90 is very good, and over 0.90 is excellent. The results in Table 2 show that the three instruments were clear and comprehensible to all of them. All three measurements show adequate levels of internal reliability.

Table 2 The Values of Cronbach's alphafor Administrative Officials

\begin{tabular}{|lcc|}
\hline \multicolumn{1}{|c}{ Dimension } & No. of Items & Cronbach's alpha \\
\hline Transformational Leadership & $\mathbf{1 2}$ & $\mathbf{0 . 8 9}$ \\
Inspirational Motivation & 2 & 0.89 \\
Intellectual Stimulation & 4 & 0.88 \\
Individual Consideration & 3 & 0.89 \\
Idealized Influence & 3 & 0.80 \\
\hline Effectiveness Strategic Implementation & $\mathbf{1 8}$ & $\mathbf{0 . 8 4}$ \\
Effectiveness & 4 & 0.84 \\
Service Quality & 4 & 0.83 \\
Competency of Servants & 6 & 0.80 \\
Innovation & 4 & 0.87 \\
\hline Organizational Culture & $\mathbf{3 6}$ & $\mathbf{0 . 8 7}$ \\
Involvement & 9 & 0.75 \\
Consistency & 9 & 0.91 \\
Adaptability & 9 & 0.81 \\
Mission & 9 & 0.90 \\
\hline
\end{tabular}

\subsection{Data Analysis Technique}

For data analysis, this study uses descriptive statistics, for example, frequency, percentage, mean, variance, and standard deviation to describe data. Exploratory factor analysis is conducted to evaluate the validity and reliability of measurement scales (Hair et al, 2010). Inferential statistics, for example, correlation and regression analysis are used to test the relationship between variables and hypothesis of this study.

\section{Conclusion}

Many factors include leadership and organizational culture influence in effective strategic implementation. This study considers in the role of transformational leadership in effective strategic implementation with the moderating effect of organizational culture. Quantitative method is conducted. The study uses the case study of administrative officials in municipalities in Trang Province, Thailand. This study integrates the context of strategic management, leadership, and organizational culture for 
testing the conceptual framework. The study is particularly useful for improving the roles of administrative officialsin order to achieve effective strategic in municipalities.

\section{Reference}

Awamleh, R. \& Gardner, W.L. (1999).Perceptions of leader charisma and effectiveness: The effects of vision content, delivery, and organizational performance. Leadership Quarterly, 10, 345-373.

Ahmadi, S. Ali Akbar; Salamzadeh, Y.; Daraei, M.; Akbari, J. (2012). Relationship between Organizational Culture and Strategy Implementation: Typologies and Dimensions.Global Business and Management Research; Boca Raton 4.3/4, 286-299.

Alvesson, M. (1989).Concepts of organizational culture and presumed links to efficiency.International Journal of Management Science, 17(4), 323-333.

Ashkenas R. \& Francis S. (2000). Integration managers: Special leaders for special times. Harvard Business Review, 78(6), 108-116.

Atkinson, H. (2006). Strategy implementation: a role for the balanced scorecard. Management Decision, 44(10), $1441-1460$.

Avolio, B. J., Bass, B.M., Walumbwa F. O., \& Zhu, W. (2004).MLQ Multifactor Leadership Questionnaire (3rd Ed.).CA: Mind Garden.

Barnat, R. (2014). Strategic management: Formulation and implementation. Retrieve from http://www.strategy-implementation.24xls.com/en136.

Bass, B. M. (1999). Bass \&Stogdill's handbook of leadership. New York: The Free Press.

Bass, B. M. \&Avolio, B. J. (2000).Improving organizational effectiveness through transformational leadership. Thousand Oaks, CA: Sage Publications.

Beer, M., \&Nohria, N. (2000).Cracking the code of change.Harvard Business Review, 78 (3), 133-141.

Bryson, J.M. (1989). Strategic planning for public and nonprofit organizations: A guide to strengthening and sustaining organizational achievement. CA:Jossey-Bass Publisher

Cater, T., \&Pucko, D. (2010). Factors of effective strategy implementation: Empirical evidence from Slovenian business practice. Journal for East European Management Studies, 15(3), 207-236.

Cavazotte, F., Moreno, V., \&Hickmann, M. (2012).Effects of leader intelligence, personality and emotional intelligence on transformational leadership and managerial performance.The Leadership Quarterly, 23(3), 443-455.

Chaimankong, M., \&Prasertsakul, D. (2012). Impact of strategy implementation on performance of generic strategy: Evidence from Thailand. The South East Asian Journal of Management, 6(1), 113.

Dewar, C., Blackburn, S., Nielsen, B. A., Irons, E., Keller, S., Ulosevich, G., \& Wood, C. (2011).How do I transform my organization's performance? USA: Mckinsey\& Company.

Dodek, P., Cahill, N.E.,Heyland, D.K. (2010). The relationship between organizational culture and implementation of clinical practice guidelines: a narrative review. Journal of Parenteral and Enteral Nutrition, 34(6), 669-674.

Eisenhardt, K.M. \& Martin, J.A. (2000). Dynamic Capabilities: What are they? Strategic Management Journal. 21 (10/11): 1105.

Fey, F.C., \&Denison, D.R. (2003). Organizational culture and effectiveness: Can American theory be applied in Russia? Organization Science, 14(6), 686-706.

Gang, W., In-Sue On, Courtright, H. S., \& Colbert, A. (2011). Transformational leadership and performance across criteria and levels: A meta-analytic review of 25 years of research. Group \& Organization Management, 36(2) 223-270.

Gracia-Morales, J. V., Jiménez-Barrionuevo, M. M., \& Gutiérrez-Gutiérrez, L. (2012). Transformational leadership influences on organizational performance through organizational learning and innovation. Journal of Business Research, 65, 1040-1050.

Hair, J.F., Andersson, R.E., Tatham, R.L., \& Black, W.C. (2010). Multivariate data analysis. New Jersey: Prentice Hall International Inc.

Hair, J. F., Money, A. H., Samouel, P., \& Page, M. (2006).Research methods for business.New York: John Wiley \& Son, Ltd. 
Herold, D., Fedor, D., Caldwell, S., \& Liu, Y. (2008). The effects of transformational and change leadership on employees' commitment to a change: A multilevel study. Journal of Applied Psychology, 93, 346-357.

Hrebiniak, L.G. (2006). Obstacles to effective strategy implementation.Organization Dynamics, 35, 1231.

Jonk, J., \&Ungerath, M. (2006).Mergers and acquisitions: Not so fast - Companies need to pace themselves during the integration process. Financier Worldwide.

Jooste, C. \&Fourie, B. (2009). The role of strategic leadership in effective strategy implementation: Perceptions of South African strategic leaders. Southern African Business Review, 13, 51-68.

Kaplan, R. S. \& Norton, D. P. (1992). The Balanced Scorecard: Measures that drive performance. Harvard Business Review, (January-February): 71-79.

Krejcie, R.V. \& Morgan, D.W. (1970).Determining sample size for research activities.Educational and Psychological Measurement, 30, 607-610.

Lismen L.M. Chan, Margaret A. Shaffer \& Ed Snape. (2007). In search of sustained competitive advantage: the impact of organizational culture, competitive strategy and human resource management practices on firm performance.The International Journal of Human Resource Management.15(1), 17-35.

Mantere, S. (2000).Sense making in strategy implementation.Unpublished Dissertation, Helsinki University of Technology, Finland.

Mektrairat, N. Rathamarit, N., Waranyuwattana, S., Laowakul, D., Chatchawan, S., Wongpredee, A., \&Leangprapath, W. (2009).The report of the progress of decentralization in Thailand and the proposals. Bangkok: Department of Local Administration.

Mushtaq, A. L. (2008). Validity of Denison's Model of Organizational Culture and Effectiveness in the Indian Context.The Journal of Business Perspective, 49-56.

Nagai-, F., Mektrairat, N., \&Funatsu, T. (2008).Local government in Thailand: Analysis of the local administrative organization survey. Japan: Institute of Developing Economies Japan External Trade Organization.

Noble, C.H. (1999).Building the strategy, implementation network.Business Horizon, 19 - 27.

Noble, C.H. (1999).The eclectic roots of strategy implementation research.Journal of Business Research, 45, $119-134$.

Nutt, P.C. (1986). Tactics of implementation.Academy of Management Journal.29 231-261.

Omondi, P. M. (2013). Factors affecting effective strategy implementation for attainment of millennium development goal 5 by international reproductive health non-governmental organizations in Kenya.The TQM Journal, 25(5).

Office of the Public Sector Development Commission. (2009). Handbook of public sector quality management development. Bangkok: Author.

Rajasekar, J. (2014). Factors affecting effective strategy implementation in a service industry: A study of Electricity Distribution Companies in the Sultanate of Oman. International Journal of Business and Social Science, 5(9), 169-183.

Raps, A. (2004).Implementing strategy.Strategic Finance, 85(12), 48-53.

Robbins, S. P. and Sanghi, S. (2007). Organizational Behavior, Pearson Education, New Delhi.

Schaap, J. I. (2006).Toward strategy implementation success: An empirical study of the role of seniorlevel leaders in the Nevada Gamming Industry. UNLV Gamming Research \& Review Journal, 10, 13-37.

Schein, E.H. (2009). Organizational culture and leadership: A dynamic view. San Francisco: Jossey-Bass Publishers.

Steiner, A. (2004). Top management planning. New York: Macmillan.

Sullivan, E. J. \& Decker, P (2012). Effective Leadership and Management in Nursing.Prentice Hall.

Thamrin, H. M. (2012). The influence of transformational leadership and organizational commitment on job Satisfaction and employee performance.International Journal of Innovation, Management and 
Technology; Singapore 3.5 (Oct 2012): 566.

Thobani, D. (2011). Factors effecting strategy implementation and the role of middle managers in implementation. Unpublished doctoral dissertation. University of Stellenbosch, South of Africa.

Van Buul, M. (2010), Successful strategy implementation: A job for the internal auditor? UnpublishedMasterDissertation. University of Amsterdam, Netherlands.

Van Der Maas, A. (2008). Strategic implementation in a small island community: An integrative framework. UnpublishedDoctoralDissertation.Erasmus University of Rotterdam, Netherlands.

Waldman, D. A., Javidan, M., \&Varella, P. (2004). Charismatic leadership at the strategic level: A new application of upper echelons theory. The Leadership Quarterly, 15, 355-380.

Zheng,W., Yang, B. and McLeanN. G.(2010)Linking organizational culture, structure, strategy, and organizational effectiveness: Mediating role of knowledge management. Journal of Business Research, 63(7), 763-771. 